\title{
PENGGUNAAN MULTIMEDIA PEMBELAJARAN INTERAKTIF MATERI PANCADHAMMA TERHADAP MINAT BELAJAR SISWA
}

\author{
Dwiyono Putranto \\ STAB Negeri Raden Wijaya Wonogiri \\ Pak.dwiyonoputranto@gmail.com
}

\begin{abstract}
Abstrak
Minat belajar di SMP N 2 Donorojo cenderuh masih rendah hal ini dapat dilihat dari hasil observasi peneliti pada saat melakanakan tugas PPL (Praktik Pengalaman Lapangan) di SMP N 2 Donorojo, Masalah yang terjadi adalah kurangnya minat dalam belajar pendidikan agama Buddha dari masingmasing siswa. salah satu masalah yang timbul adalah guru dalam menyampaikan bahan pelajaran hanya menggunakan bahasa lisan atau tulisan dan jarang sekali disertai alat pendukung yang lebih konkrit yang dapat memperjelas materi yang disampaikan sehingga kurang adanya minat belajar yang tinggi dari siswa. Peneliti kemudia melakukan penelitian dengan menggunakan multimedia pembelajaran interaktif dalam menyampaikan materi pembelajaran Pancadhamma. Metode yang digunakan dalam penelitian ini adalah metode eksperimen, jumlah sampel yang diambil sebanyak 24 siswa. Instrumen yang digunakan adalah analisis data dilakukan dengan analisis non parametrik teknik t-test. Berdasarkan hasil persentase Analisis t-test menunjukkan bahwa Penggunaan media Media Pembelajaran Interaktif Pendidikan Agama Buddha berpengaruh signifikan terhadap Minat Belajar Pendidikan Agama Buddha pada siswa kelas VII SMP N 2 Donorojo. Hal ini terbukti dari hasil statistik paired sample t test yang menunjukkan bahwa nilai Asymp. Sig lebih kecil dibandingkan dengan daftar pada taraf signifikan 5\% yaitu 0,000 $\leq 0,03$. Selanjutnya, pencapaian Minat belajar juga mempunyai nilai yang baik. Nilai rata-rata pree test atau sebelum perlakuan 58\% dengan kategori CUKUP dan setelah diberi perlakuan atau post test meningkat sebesar 70\%, Sehingga secara keseluruhan Minat belajar siswa setelah penggunaan Media Pembelajaran Interaktif diperoleh rata-rata sebesar 70\% dan termasuk dalam kategori TINGGI.
\end{abstract}

Kata kunci: Media Pembelajaran Interaktif, Minat Belajar

\begin{abstract}
Interest in studying at SMP N 2 Donorojo tends to be low, this can be seen from the results of observations of researchers when carrying out PPL assignments (Practice Field Experience) at SMP N 2 Donorojo, the problem that occurs is the lack of interest in learning Buddhist education from each student. One of the problems that arise is that teachers in delivering lesson materials only use spoken or written language and are rarely accompanied by more concrete supporting tools that can clarify the material presented so that there is a lack of high learning interest from students. The researcher then conducted research using interactive multimedia learning in delivering Pancadhamma learning materials. The method used in this research is the experimental method, the number of samples taken is 24 students. The instrument used was data analysis performed with non-parametric analysis of the t-test technique. Based on the results of the percentage t-test analysis showed that the use of Interactive Learning Media Media for Buddhist Education has a significant effect on Interest in Learning Buddhist Education in grade VII students of SMP N 2 Donorojo. This is evident from the statistical results of the paired sample t test which shows that the Asymp value. Sig is smaller than the list at a significant level of 5\%, namely 0.000 0.03. Furthermore, the achievement of learning interest also has a good value. The average value of pree test or before treatment was 58\% with ENOUGH category and after being given treatment or post test increased by $70 \%$, so that
\end{abstract}

Al Qalam: Jurnal Ilmiah Keagamaan dan Kemasyarakatan Vol. 16, No. 1

Januari - Juni 2022 
Dwiyono Putranto : Penggunaan Multimedia Pembelajaran Interaktif Materi Panchadamma Terhadap Minat Belajar Siswa

overall student learning interest after using Interactive Learning Media obtained an average of $70 \%$ and included in the HIGH category.

Keywords: Interactive Learning Media, Interest in Learning

\section{PENDAHULUAN}

Lembaga pendidikan SMP N 02 Donorojo memiliki tujuan yang tidak terlepas dari tujuan pendidikan menengah pertama secara umum. Sinergi dengan faktor sumber daya manusia, sarana dan prasarana, SMP N 2 Donorojo diharapkan dapat menciptakan pembelajaran lebih bersifat mendidik, membangkitkan aktifitas dan kreatifitas siswa, efektif dan demokratis. Sejalan dengan hal itu pembelajaran akan menjadi lebih menyenangkan bagi siswa.

Menurunya minat belajar siswa tidak terlepas dari proses kegiatan belajar mengajar yang dilaksanakan. Kegiatan belajar mengajar memiliki tujuan untuk mengembangkan kemampuan sosial serta kemampuan akademik peserta didik. Mengingat kekhasan mata pelajaran pendidikan agama Buddha, cara penyajian pelajaran atau metode mengajar di SMP N 2 Donorojo masih kurang memanfaatkan berbagai sarana penunjang yang mendukung seperti salah satunya adalah media belajar.

Media pembelajaran yang digunakan pada mata pelajaran pendidikan agama Buddha hendaknya dapat dipilih secara tepat. Jika pemilihan penggunaan media pembelajaran kurang tepat, maka akan menimbulkan masalah kepada para siswa yang berakibat minat belajar menjadi menurun. Untuk itu pembelajaran dengan menggunakan media, khususnya media interaktif dapat dijadikan sebagai salah satu alternatif untuk hal atau permasalahan tersebut.

Berdasarkan Praktik Pengalaman Lapangan yang dilakukan peneliti sebelumnya, di SMP N 2 Donorojo peneliti menemukan suatu masalah mengenai minat belajar pendidikan agama Buddha pada siswa kelas VII. Masalah yang terjadi adalah kurangnya minat dalam belajar pendidikan agama Buddha dari masing-masing siswa. Setelah melalui observasi singkat, salah satu masalah yang timbul adalah guru dalam menyampaikan bahan pelajaran hanya menggunakan bahasa lisan atau tulisan dan jarang sekali disertai alat pendukung yang lebih konkrit yang dapat memperjelas materi yang disampaikan sehingga kurang adanya minat belajar yang tinggi dari siswa. Konsekuensinya diperlukan media pembelajaran yang dapat membantu mereka dalam memahami pelajaran pendidikan agama Buddha. Salah satunya adalah melalui penggunaan media belajar interaktif. Melalui media ini disamping mampu memberikan gambaran yang lebih kongkrit juga dipandang lebih menarik, sehingga diharapkan dapat meningkatkan minat belajar siswa yanglebih baik.

\section{KAJIAN PUSTAKA}

Al Qalam: Jurnal Ilmiah Keagamaan dan Kemasyarakatan Vol. 16, No. 1 Januari - Juni 2022 
Dwiyono Putranto : Penggunaan Multimedia Pembelajaran Interaktif Materi Panchadamma Terhadap Minat Belajar Siswa

Minat adalah ketertarikan seseorang terhadap objek tertentu, dalam kaitannya dengan karier, minat berperan penting untuk mengarahkan individu dalam pilihan karier atau pekerjaan. Apabila muncul keraguan pada minat, maka individu akan merasa kesulitan dalam mengambil keputusan karier. Tingginya minat generasi muda terhadap pentingnya pendidikan dipengaruhi minat pada pekerjaan untuk kedepannya. Generasi muda dominan menaruh minat pada mata pelajaran yang dinilai sesuai pada bidang pekerjaan yang diharapkan.

Jersild dan Tasch menekankan bahwa minat adalah aktivitas yang dipilih secara bebas oleh individu. Sedangkan Doyles Fryer minat merupakan gejala psikis yang berhubungan dengan aktivitas yang menstimulus perasaan terhadap individu (Nurkancana, 1986:229). ${ }^{1}$

Minat merupakan kecenderungan untuk memperhatikan beberapa kegiatan. Aktifitas yang dilaksanakan setiap individu disertai dengan rasa sayang dan tanggung jawab. Minat jua diartikan sebagai kecenderungan atau daya tarik pada bidang tertentu dan menikmati bidangnya. Minat merupakan kondisi yang nyata apabila melihat arti sementara kondisi yang dihubungkan dengan kebutuhan sendiri (Sardiman.2001:72). ${ }^{2}$

Minat belajar dalam agama Buddha adalah cetana atau kehendak untuk berbuat baik atau yang tidak baik (Pandit, 2005:130). ${ }^{3}$ Cetana adalah salah satu faktor mental (cetasika) yang memimpin kesadaran pikiran dan faktor mental lainnya yang muncul bersamanya.

Minat dalam agama Buddha dapat diartikan sebagai tekad (adhitana), Upaya Kausalya. Upaya (keterampilan dalam cara), Pranidhana (ikrar atau tekad), Bodhisattwa dikatakan menggunakan setiap cara atau jalan yang sangat memungkinkan untuk membimbing mahlukmahluk menuju pencerahan, upaya berarti jalan yang berguna, taktik, keterampilan sebagai teknis dalam agama Buddha. penggunaan istilah ini dibedakan dalam intelegensi (prajna) dan dianggap sinonim dengan belas kasih (karuna).

Multimedia interaktif diartikan sebagai media yang digunakan dalam proses pembelajaran, atau digunakan untuk menyalurkan pengetahuan, keterampilan, dan sikap, serta dapat merangsang pikiran, perasaan, perhatian, dan kemauan untuk belajar sehingga proses belajar terkendali (Ariani, Haryanto,2010:26). ${ }^{4}$

\footnotetext{
${ }^{1}$ Nurkancana Wayan. 1986. Evaluasi Pendidikan. Surabaya: Usaha Nasional, hlm 229.

2 Sardiman, A. M. 2001. Interaksi dan Motivasi Belajar Mengajar. Jakarta: PT Raja Grafindo Persada, hlm 72.

${ }^{3}$ Kaharuddin Pandit j. 2005. Abhidhammathasangaha. Tangerang: Vihara Padumutara, hlm 130. hlm 26 .

${ }^{4}$ Ariani, Harianto. 2010. Pembelajaran Multimedia di Sekolah. Jakarta. Prestasi pustaka,
}

Al Qalam: Jurnal Ilmiah Keagamaan dan Kemasyarakatan Vol. 16, No. 1 Januari - Juni 2022 
Dwiyono Putranto : Penggunaan Multimedia Pembelajaran Interaktif Materi Panchadamma Terhadap Minat Belajar Siswa

Ahli dalam Model Pembelajaran Multimedia Interaktif mengemukakan bahwa model pembelajaran Multimedia Interaktif diartikan sebagai suatu model pembelajaran yang dapat digunakan untuk menyalurkan pesan, merangsang pikiran, perasaan, perhatian, dan kemauan siswa sehingga dapat mendorong proses belajarnya. Assosiasi Teknologi dan Komunikasi (Assosiation of Educatian and Communication Technology) di Amerika memberi batasan bahwa media merupakan bentuk dan alat yang digunakan orang untuk menyalurkan informasi, dan media bias diartikansebagai jenis komponen yang dapat merangsang peserta didik untuk belajar.

Agar belajar mengajar dapat berlangsung dengan baik, harus ada persiapan. Kesiapan mengajar dan kesiapan belajar sama pentingnya. Teknik untuk kesiapan dalam memulai belajar, ditunjukkan oleh Buddha, misalnya dengan memberi makan kepada siswa yang lapar sebelum Buddha menyampaikan khotbahnya dengan siswanya (DhpA. 203). ${ }^{5}$

Penyampaian ajaran dilakukan dengan pendekatan individu atau kelompok. Ceramah diberikan secara sistematis, agar mudah diingat, penyampaian materi dapat diberi urutan nomor, dikelompokkan menurut tema dan berdasarkan jumlah butir uraian yang ditemukan dalam Kitap Suci Anguttara-Nikaya. Buddha sering mengulang khotbahnya yang penting dalam berbagai kesempatan. "mengulang pengetahuan yang penting akan mendapatkan manfaat" (A. III, 136). ${ }^{6}$

\section{METODE PENELITIAN}

\section{a. Obyek Penelitian}

Obyek penelitian yang diteliti adalah seluruh siswa kelas VII SMP N 2 Donorojo Kab. Jepara, obyek penelitian berjumlah 24 siswa yang beragama Buddha dengan jumlah laki-laki 15 siswa dan perempuan 10 siswa.

\section{b. Desain Penelitian}

Desain penelitian mengunkan bentuk Pre-Experimental Designs. Karena dalam penelitian ini tidak menggunkan variabel kontrol, dan sampel tidak dipilih secara rondom. Bentuk penilitian yang di gunakan jenis one-group Pretest-posttest design.

\begin{tabular}{|c|c|c|}
\hline Pre test & Perlakuan & Post test \\
\hline O1 & Media Interaktif & O2 \\
\hline
\end{tabular}

Gambar 1: Desain pretest-posttest

${ }^{5}$ Dhammapada A. 2005. Kisah-kisah Dhammapada. Medan: karya Maju, hlm 203.

${ }^{6}$ Angutara Nikaya III. 2003. Numerical Discourses Of the Buddha. Klaten: Vihara Bodhivamsa, hlm 136.

Al Qalam: Jurnal Ilmiah Keagamaan dan Kemasyarakatan Vol. 16, No. 1 Januari - Juni 2022 
Dwiyono Putranto : Penggunaan Multimedia Pembelajaran Interaktif Materi Panchadamma Terhadap Minat Belajar Siswa

$\mathbf{O}_{1}=$ Nilai Pretest $($ Sebelum Diberi Perlakuan)

$\mathbf{O}_{2}=$ Nilai Posttest (Setelah Diberi Perlakuan)

$\mathbf{X}=$ Perlakuan

Pengaruh multimedia interaktif terhadap minat belajar siswa SMP N 2 Donorojo $=\left(\mathbf{O}_{\mathbf{1}}-\mathbf{O}_{2}\right)$.

\section{c. Teknik Pengumpulan Data}

Bentuk dan skor jawaban angket terdiri dari lima jawaban yaitu: sangat sesuai, sesuai, ragu ragu, tidak setuju, dan sangat tidak setuju. Agar peryataan ini dapat dianalisis secara setatistik maka ke lima katergori jawaban ini memiliki skor dari 1 sampai 5. Cara untuk penyekoran dari masing-masing kategori jawaban adalah sebagai berikut:

Table 1: Penyekoran skala angket

\begin{tabular}{|c|c|c|}
\hline No & Jawaban & Skor \\
\hline 1 & Sangat Setuju & 5 \\
\hline 2 & Setuju & 4 \\
\hline 3 & Ragu-ragu & 3 \\
\hline 4 & Tidak Setuju & 2 \\
\hline 5 & Sangat Tidak Setuju & 1 \\
\hline
\end{tabular}

Sumber : Sugiono, 2012:94

\section{d. Uji Validitas dan Reliabilitas}

(1) Validitas

Hasil penelitian yang valid bila terdapat kesamaan antara data yang terkumpul dengan data yang sesungguhnya terjadi pada obyek yang diteliti. Kalau dalam obyek berwarna merah, sedangkan obyek yang terkumpul berwarna putih, maka hasil penelitian tidak valid. Valid berarti instrumen tersebut dapat digunakan untuk mengukur apa yang seharusnya memang diukur.

Teknik uji validitas untuk menentukan validitas terhadap item-item skala angket dengan menggunkan rumus korelasi product moment. Pengujian validitas dibantu software komputer Statistical Package for The Social Sciences (SPSS 16).

(2) Reliabilitas

Teknik yang dipakai untuk menentukan reliabilitas (keajegan) instrumen adalah dengan rumus Alpha. Peneliti menggunakan rumus ini karena instrumen yang dipergunakan berbentuk sakala angket dengan skor skala bertingkat. Untuk angket dengan skala

Al Qalam: Jurnal Ilmiah Keagamaan dan Kemasyarakatan Vol. 16, No. 1 Januari - Juni 2022 
Dwiyono Putranto : Penggunaan Multimedia Pembelajaran Interaktif Materi Panchadamma Terhadap Minat Belajar Siswa

bertingkat diuji dengan menggunakan rumus Alpha. Pengujian reliabilitas dibantu software komputer Statistical Package for The Social Sciences (SPSS 16).

\section{e. Teknik Pengambilan Sampel}

Penelitian ini menggunakan teknik pengambilan sampel yaitu purposive sampling atau sampel bertujuan ini dilakukan karena peneliti hanya memiliki satu kelompok populasi. Sampel diambil dari seluruh siswa kelas VII SMP N 2 Donorojo yang beragama Buddha yang berjumlah 24 siswa.

\section{f. Analisis diskripstif Variabel}

Analisis deskriptif digunakan untuk menjabarkan sejumlah data agar memperoleh gambaran secara sistematis dan menyeluruh mengenai keadaan subyek penelitian. Deskripsi data subyek penelitian ini meliputi gambaran hasil penelitian secara umum meliputi mean, standar deviasi, rentang prosentase skor, perhitungan frekuensi dan prosentase.

\section{g. Uji Normalitas Data}

Uji normalitas digunakan untuk mengetahui apakah populasi data berdistribusi normal atau tidak. Uji normalitas biasanya digunakan untuk mengukur data bersakala ordinal, interval, atau pun rasio. Untuk mengetahui hasil uji normalitas dibantu software komputer Statistical Package for The Social Sciences (SPSS 16).

\section{h. Uji Hipotesis}

Metode dan teknik analsis data dipergunakan untuk menjawab permasalahan penelitian yang telah dirumuskan, data yang dikumpulkan dianalisa dengan menggunakan T-test . Data yang dikumpulkan akan di analisis dengan menggunakan rumus $t$-test berkorelasi yaitu paired sample t-tes, dibantu software komputer Statistical Package for The Social Sciences (SPSS 16).

\section{HASIL PENELITIAN DAN PEMBAHASAN}

\section{a. Gambaran Umum Objek Penelitian}

Obyek penelitian yang diteliti adalah seluruh siswa kelas VII SMP N 2 Donorojo, Kab. Jepara, obyek penelitian berjumlah 24 siswa yang beragama Buddha dengan jumlah laki-laki 14 dan perempuan 10. Penelitian ini di tujukan pada siswa kelas VII, karena di SMP N 2 Donorojo kelas VII sudah dilengkapi dengan liquid crystal display (LCD) proyektor, sehingga memudahkan pengaplikasian penggunaan multimedia pembelajaran interaktif.

\section{b. Hasil Penelitian}

\section{Hasil Uji Validitas}

Hasil dari uji coba instrument skala angket minat belajar siswa SMP N 2 Donorojo kelas VII, diperoleh informasi bahwa dari 50 item terdapat 41 item yang valid, sedangkan

Al Qalam: Jurnal Ilmiah Keagamaan dan Kemasyarakatan Vol. 16, No. 1 Januari - Juni 2022 
Dwiyono Putranto : Penggunaan Multimedia Pembelajaran Interaktif Materi Panchadamma Terhadap Minat Belajar Siswa

item yang tidak valid terdapat 9 yang kemudian item tersebut dibuang, item yang tidak valid yaitu pada nomor 15, 31, 33, 36, 40, 41, 43, 47, 50 dengan menggunakan 24 responden. Dari 50 item yang di uji cobakan terdapat 41 item yang valid, di dapat indeks korelasi tertinggi 0,828 dan indeks korelasi terendah yaitu 0,414. Hasil lengkap uji validitas instrumen dapat dilihat pada lampiran uji validitas.

\section{a. Hasil Uji Reliabilitas}

\section{Reability Statistics}

\begin{tabular}{|ll|r|}
\hline & & \multicolumn{1}{|c|}{ X } \\
\hline Normal Parameters & \\
& & Mean \\
& Std. Deviation & 24 \\
Most Extreme & Absolute & .730 .83 \\
Differences & Positive & .104 \\
& Negative & -.101
\end{tabular}

Dari 50 item yang diujikan kemudian terdapat 41 item yang valid, dan item yang tidak valid dibuang. Hasil pengujian 51 item diperoleh reliability analisis scale (alpha) dengan menggunakan software SPSS 16 menghasilkan alpha 0,955 meningkat dari hasil uji reliabilitas 50 item sebelumnya. Alat ukur minat belajar siswa yang dilakukan peneliti memiliki kriteria yang reliable dengan skor alpha yaitu 0.955 , karena lebih dari 0.7 bahkan dapat disimpulkan baik karena berada jauh di atas 0,8 .

\section{b. Hasil Uji Normalitas}

\section{One-Sample Kolmogorov-Smirnov Test}

\begin{tabular}{|r|r|}
\hline $\begin{array}{c}\text { Cronbach's } \\
\text { Alpha }\end{array}$ & N of Items \\
\hline .955 & 41 \\
\hline
\end{tabular}

Al Qalam: Jurnal Ilmiah Keagamaan dan Kemasyarakatan Vol. 16, No. 1 Januari - Juni 2022 
Dwiyono Putranto : Penggunaan Multimedia Pembelajaran Interaktif Materi Panchadamma Terhadap Minat Belajar Siswa

\begin{tabular}{|l|r} 
Kolmogorov-Smirnov Z & .509 \\
Asymp. Sig. (2-tailed) & .958 \\
\hline
\end{tabular}

a. Test distribution is Normal.

Berdasarkan hasil uji normalitas menggunkana statistic non-parametrik one sample kolmogorov-smirnov test instrumen minat belajar siswa menunjukan hasil berdistribusi normal, setelah dilakukan perlakuan diketahui probabilitas signifikan sebesar 0,958. Probabilitas signifikan jauh berada diatas 0,05 yang berat data yaitu ditrima.

\section{c. Hasil Uji T-Test}

Paired Samples Statistics

\begin{tabular}{|ll|l|r|r|r|}
\hline & \multicolumn{1}{|c|}{ Mean } & \multicolumn{1}{c|}{$\mathrm{N}$} & Std. Deviation & $\begin{array}{c}\text { Std. Error } \\
\text { Mean }\end{array}$ \\
\hline Pair1 pre & 130.83 & 24 & 29.732 & 6.069 \\
& post & 139.75 & 24 & 20.165 & 4.116 \\
\hline
\end{tabular}

Berdasarkan data statistik di atas, diperoleh rata-rata minat belajar siswa SMP N 2 Donorojo, rata-rata sebelum penggunaan multimedia pembelajaran interaktif sebesar 130,83 dan rata-rata sestelah penggunaan multimedia pembelajaran interaktif materi Pancadhamma sebesar 139,75. Dengan demikian berarti terjadi peningkatan nilai ratarata minat belajar siswa sebelum dan setelah perlakuan.

Paried Srantes Iest

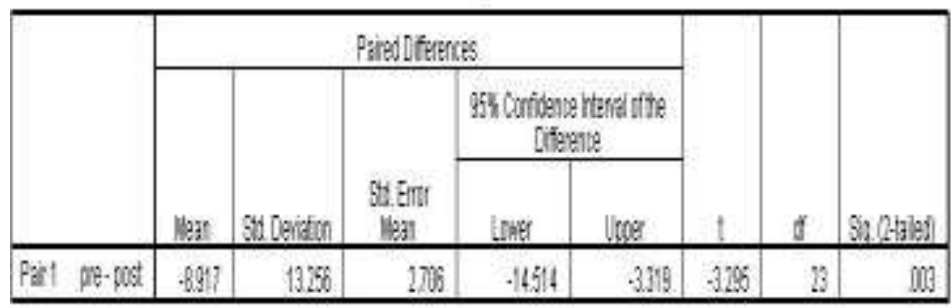

Dari data statistik Paired Sample test diatas diperoleh hasil t hitung untuk minat belajar siswa adalah sebesar - 3,295 dengan propabilitas Sig (2-tailed) 0,003 $<0,05$, maka Ho ditolak dan Ha diterima. Hal ini mengasumsikan bahwa penggunaan multimedia pembelajaran interaktif materi Pancadhamma berpengaruh terhadap minat belajar siswa SMP N 2 Donorojo kelas VII.

\section{PEMBAHASAN}

Berdasarkan data statistik di pada tabel 4.10 diperoleh rata-rata minat belajar siswa SMP N 2 Donorojo, rata-rata sebelum penggunaan multimedia pembelajaran interaktif sebesar 130,83 dan

Al Qalam: Jurnal Ilmiah Keagamaan dan Kemasyarakatan Vol. 16, No. 1 Januari - Juni 2022 
Dwiyono Putranto : Penggunaan Multimedia Pembelajaran Interaktif Materi Panchadamma Terhadap Minat Belajar Siswa

rata-rata sestelah penggunaan multimedia pembelajaran interaktif dharmayatra sebesar 139,75. Dengan demikian berarti terjadi peningkatan nilai rata-rata motivasi belajar siswa sebelum dan setelah perlakuan.

Hasil penelitian menunjukkan bahwa minat belajar siswa SMP N 2 Donorojo kelas VII sebelum dan setelah adanya perlakuan menggunakan multimedia pembelajaran interaktif diperoleh hasil t -3,295 dan menunjukkan adanya pengaruh yang signifikan. hal ini ditandai dengan probabilitas signifikan sebesar 0,003 . Sedangkan skor rata-rata yang diperoleh dari postest minat belajar siswa mengalami peningkatan dibanding sebelum dilakukan perlakuan dengan menggunkan multimedia pembelajaran interaktif. Peningkatan minat belajar siswa SMP N 2 Donorojo kelas VII sebelum dan sesudah perlakuan adalah sebesar -8,917.

Menurut Zainal Aqip, mengatakan bahwa manfaat media adalah untuk Menyeragamkan penyampaian materi sehingga memperjelas penyajian pesan (tidak verbalis), Pembelajaran lebih jelas dan menarik sehingga mengatasi keterbatasan ruang, waktu, dan daya indra, Proses pembelajaran lebih interaksi sehingga objek bisa besar/kecil, Efisiensi waktu dan tenaga sehingga gerak bisa cepat/lambat, Meningkatkan kualitas hasil belajar sehingga kejadian masa lalu, objek yang kompleks, Belajar dapat dilakukan kapan saja dan dimana saja sehingga konsep bisa luas atau sempit, Menumbuhkan sifat positif belajar terhadap proses dan materi belajar sehingga mengatasi sikap pasif peserta, Meningkatkan peran guru kearang yang lebih positif dan produktif sehingga menciptakan persamaan pengalaman, dan persepsi peserta yang heterogen.

Untuk menjawab hipotesis atau kebenaran sementara yaitu "apakah ada pengaruh penggunaan multimedia pembelajaran interaktif terhadap minat belajar siswa kelas VII SMP N 02 Donorojo semester genap materi Pancadhamma. Maka dari hasil penelitian menunjukan bahwa dari uji paired sample t-test diperoleh $t$ hitung untuk motivasi belajar siswa sebesar -3,295 dengan nilai probabilas sebesar 0,003 . Dengan demikian dinyatakan $0,003<0,05$ sehingga Ho ditolak dan Ha diterima. Jadi dapat disimpulkan dalam penelitian ini terdapat pengaruh multimedia pemebelajaran interaktif terhadap minat belajar siswa SMP N 2 Donorojo kelas VII materi Pancadhamma.

\section{SIMPULAN DAN SARAN}

Minat belajar siswa dapat meningkat dikarenakan penggunaan media yang menarik dan mampu memberikan rasa senang atau keinginan kepada siswa. Siswa mampu menerima pembelajaran dengan baik, dikarenakan minat siswa yang tinggi juga membantu siswa dalam mencapai keberhasilan dalam pembelajaran.

a. Simpulan

Al Qalam: Jurnal Ilmiah Keagamaan dan Kemasyarakatan Vol. 16, No. 1

Januari - Juni 2022 
Dwiyono Putranto : Penggunaan Multimedia Pembelajaran Interaktif Materi Panchadamma Terhadap Minat Belajar Siswa

Berdasarkan dari hasil penelitian, pengolahan data dan analisis data pada pengaruh penggunaan media interaktif pancadhamma terhadap minat belajar pendidikan agama Buddha. maka kesimpulan dari penelitian ini adalah:

Penggunaan media interaktif berpengaruh signifikan terhadap minat belajar Pendidikan Agama Buddha pada siswa kelas VII SMP Negeri 02 Kecamatan Donorojo Kabupaten Jepara. Hal ini terbukti dari hasil statistik paired sample t test yang menunjukkan bahwa nilai Asymp. Sig lebih kecil dibandingkan dengan daftar pada taraf signifikan $5 \%$ yaitu $0,003 \leq 0,05$. Selanjutnya, pencapaian minat belajar Pendidikan Agama Buddha pada siswa SMP N 02 Donorojo sebelum pembelajaran menggunakan media interaktif atau sebelum diadakan perlakuan memiliki nilai rata-rata sebagai berikut: Nilai rata-rata pada aspek rasa senang $62 \%$; aspek perhatian sebesar 61\%; dan aspek ketertarikan sebesar 52\%. Sehingga secara keseluruhan minat belajar siswa sebelum penggunaan media interaktif atau sebelum perlakuan diperoleh rata-rata sebesar 58\% dan termasuk dalam kategori cukup.

Pencapaian minat belajar Pendidikan Agama Buddha pada siswa SMP N 02 Donorojo sesudah diadakan perlakuan memiliki nilai rata-rata sebagai berikut: Nilai rata-rata pada aspek rasa senang $71 \%$; aspek perhatian sebesar $71 \%$; dan aspek ketertarikan sebesar $69 \%$. Sehingga secara keseluruhan minat belajar siswa sesudah penggunaan media interaktif atau sesudah perlakuan diperoleh rata-rata sebesar $70 \%$ dan termasuk dalam kategori tinggi.

Minat belajar siswa dipengaruhi penggunaan media interaktif meliputi beberapa aspek yaitu, aspek rasa senang, perhatian, dan ketertarikan yang secara positif dapat mempengaruhi tingkat keberhasilan siswa dalam mencapai tujuan pembelajaran yang diharapkan. Hal ini dikarenakan minat belajar siswa yang tinggi juga akan membantu siswa dalam mewujudkan suatu keberhasilan dalam pembelajaran. Sebaliknya, minat belajar yang rendah akan membuat siswa merasa sulit untuk mencapai tujuan pembelajaran.

b. Saran

Saran ini ditunjukkan kepada guru mata pelajaran, guru praktik, kepala sekolah, dan peserta didik SMP N 02 Kec. Donorojo Kab. Jepara.

1. Kepala Sekolah

Kepala sekolah hendaknya dapat memanfaatkan penghargaan positif kepada semua siswa, karyawan, dan guru atau pembimbing agar para siswa, karyawan dapat prestasi baik dalam melaksanakan tugas dan tanggung jawab masing-masing, sehingga tercipta suasana harmonis di lembaga pendidikan khususnya SMP N 02 Kec. Donorojo Kab. jepara.

2. Guru Mata Pelajaran dan Guru Praktik

Sedapat mungkin para guru Agama Buddha dapat memanfaatkan media interaktif Al Qalam: Jurnal Ilmiah Keagamaan dan Kemasyarakatan Vol. 16, No. 1 Januari - Juni 2022 
Dwiyono Putranto : Penggunaan Multimedia Pembelajaran Interaktif Materi Panchadamma Terhadap Minat Belajar Siswa

dalam pengajaran Pendidikan Agama Buddha, disesuaikan dengan karakteristik materi. Minat belajar yang dimiliki siswa hendaknya perlu dipahami dan dipertimbangkan oleh para guru mata pelajaran dan guru praktik dalam proses pembelajaran agar mampu menciptakan lingkungan belajar yang kondusif dan menyenangkan. Selanjutnya, para guru hendaknya dapat memberikan penghargaan positif tanpa syarat kepada semua siswa agar lebih giat dalam belajar, menciptakan suasana dalam memenuhi dan meningkatkan minat belajarnya untuk kebahagiaan dan keberhasilan dalam hidupnya.

3. Peserta Didik

Kepada para peserta didik atau siswa hendaknya terus dapat memanfaatkan kegiatankegiatan yang diselenggarakan sekolah sebagai wahana untuk mengembangkan potensi diri serta menumbuhkan minat belajar demi tercapainya harapan dan cita-citanya di masa mendatang.

4. Penelitian Lebih Lanjut

Perlu diadakan penelitian yang serupa disetiap lembaga pendidikan baik negeri maupun swasta. Informasi tentang manfaat minat belajar perlu diperoleh di setiap jenjang pendidikan mulai dari pendidikan tingkat dasar sampai dengan perguruan tinggi.

\section{DARTAR PUSTAKA}

Angutara Nikaya III. 2003. Numerical Discourses Of the Buddha. Klaten: Vihara Bodhivamsa. Ariani, Harianto. 2010. Pembelajaran Multimedia di Sekolah. Jakarta. Prestasi pustaka.

Dhammapada A. 2005. Kisah-kisah Dhammapada. Medan: karya Maju

Kaharuddin Pandit j. 2005. Abhidhammathasangaha. Tangerang: Vihara Padumutara.

Nurkancana Wayan. 1986. Evaluasi Pendidikan. Surabaya: Usaha Nasional.

Sardiman, A. M. 2001. Interaksi dan Motivasi Belajar Mengajar. Jakarta: PT Raja Grafindo Persada.

Al Qalam: Jurnal Ilmiah Keagamaan dan Kemasyarakatan Vol. 16, No. 1 Januari - Juni 2022 